\title{
Tissue-type plasminogen activator activity in morphologically normal tissues adjacent to gastrointestinal carcinomas is associated with the degree of tumor progression
}

\author{
Received: 19 April 2005/ Accepted: 29 November 2005 / Published online: 21 December 2005
}

(C) Springer-Verlag 2005

\begin{abstract}
Purpose: To investigate whether the level of plasminogen activator (PA) activity assayed in gastrointestinal carcinomas and the "morphologically normal tissues" adjacent to them is associated with the degree of tumor progression. Methods: Tumor and "normal tissues" were obtained from gastrointestinal surgical samples to assess urokinase-type (u-PA) and tissue-type plasminogen activator (t-PA) activities by radial caseinolytic assay and the expression of PA inhibitor-1 (PAI-1) by ELISA. We compared the PA system between the tumor and "normal tissues" and we investigated the existence of correlations between: (a) PA production in the tumor and "normal tissues", (b) different components of the PA system, and (c) PA system and the degree of tumor progression. Results: (1) Total PA activity, u-PA activity and PAI-1 expression are significantly higher in tumor than in "normal tissues", whereas t-PA activity does not differ between them. (2) Total PA activity mainly correlates with u-PA activity in tumor tissues and similarly with u-PA and t-PA activities in "normal tissues". (3) There is a significant association between t-PA activity in tumor and "normal tissues" and the degree of tumor progression. Conclusions: "Morphologically normal tissues" adjacent to carcinomas present abnormal t-PA activity that is associated with the degree of tumor progression.
\end{abstract}

G. Scicolone $(\bowtie) \cdot$ V. Sanchez $\cdot$ L. Vauthay $\cdot$ F. Fuentes

A. Scicolone $\cdot$ V. Flores

School of Medicine, Institute of Cell Biology and Neurosciences,

"Prof E De Robertis", University of Buenos Aires, Paraguay 2155,

1121 Buenos Aires, Argentina

E-mail: gscicolo@mail.retina.ar

Tel.: + 54-11-59509500

Fax: + 54-11-59509626

M. Rapacioli · V. Flores

Interdisciplinary Group in Theoretical Biology,

Department of Biostructural Sciences, Favaloro University, 1078 Buenos Aires, Argentina

L. Scicolone $\cdot$ A. Scicolone

Diego Thompson Hospital, San Martin, 1650 Buenos Aires, Prov. Argentina
Assaying of this activity could be useful as a predictive parameter.

Keywords Plasminogen activator - Proteases activity · Gastrointestinal carcinomas · Tumor progression . Morphologically normal tissues

\section{Introduction}

Under normal conditions, the plasminogen activator (PA) system functions as a finely regulated mechanism of pericellular proteolysis (Andreasen et al. 2000). This system is composed of plaminogen-plasmin, plasminogen activators-tissue type (t-PA) and urokinase type (u-PA), PA inhibitors (PAIs), a membrane receptor for u-PA (u-PAR) and high affinity binding sites for t-PA (Andreasen et al. 2000; Diaz et al. 2004). PA converts plasminogen to plasmin, the latter degrades a wide range of extracellular matrix proteins and also activates matrix metalloproteases (Andreasen et al. 2000). Given that basement membrane and extracellular matrix degradations are essential events for cancer invasiveness and metastatic dissemination, the PA system also plays a relevant part in cancer progression (Andreasen et al. 2000; Herszenyi et al. 2000; Berger 2002).

Human gastrointestinal tumors display increased expression of $\mathrm{u}-\mathrm{PA}, \mathrm{u}-\mathrm{PAR}$, and PAI-1 compared with their corresponding normal tissues (Sier et al. 1993; Verspaget et al. 1995; Cho et al. 1997; Herszenyi et al. 2000; Berger 2002). The increase in the expression of these molecules associates with the tumor size and the invasiveness (Abe et al. 1999; Okusa et al. 1999; Papadopoulou et al. 2002; Baker and Leaper 2003; Kaneko et al. 2003). Other works indicate that stromal cells interact with tumor cells and express u-PA and PAI-1. These observations suggest that stromal cells that are located within the tumor could participate in cancer invasion and have a relevant influence on the evolution of the tumor (Grondahl-Hansen et al. 1991; 
Okusa et al. 1999; Kloblinski et al. 2000; Illemann et al. 2004).

Recent works show that over-expression of cyclooxygenase-2 (COX-2) increases motility and invasion of cancer cells by up-regulating u-PA production ( $\mathrm{Li}$ et al. 2002; Singh et al. 2005). Besides, COX-2 expression correlates with u-PAR levels and is associated with poor prognosis in human colorectal cancer (Konno et al. 2002). Consistently, COX inhibitors and selective COX2 inhibitors decrease tumor growth and metastatic spread by blocking u-PA production ( $\mathrm{Li}$ et al. 2002; Berger et al. 2003; Evans and Sloan Stakleff 2004; Nishikawa et al. 2004; Singh et al. 2005). Thus, u-PA seems to play a relevant role in tumor dissemination. In contrast, t-PA is currently considered to be mainly involved in intravascular fibrinolysis (Herszenyi et al. 2000) and less relevance is usually given to it in tumor biology. Nevertheless, some reports suggest that t-PA is also involved in the tumor progression (Raigoso et al. 2000; Sanz et al. 2002; Diaz et al. 2004).

Efforts have been made to demonstrate that measurements of the PA system components (u-PA, u-PAR, and PAI-1) could have prognostic value in patients with gastrointestinal carcinomas (Nekarda et al. 1994; Cho et al. 1997; Heiss et al. 1997; Skelly et al. 1997; Murata et al. 1998; Stephens et al. 1999; Yang et al. 2000; Duffy and Duggan 2004). Some studies, however, have yielded conflicting results about such a prognostic value (Fujii et al. 1999; Raigoso et al. 2000; Sanz et al. 2002). It was reported that the level of t-PA activity or its expression could also have prognostic value since the low level of tPA expression in the gastrointestinal mucosa is associated with a shorter overall survival (Verspaget et al. 1995; Ganesh et al. 1994, 1996, 1997).

Most of these studies analyze the expression of these proteases separately instead of measuring the global proteolytic activity supplied by both the PA isoforms on a defined substratum. In theory, this last parameter would reflect the effect on the extracellular matrix degradation better.

The proteolytic effect of the PA system is usually quantified in samples of tissue homogenates or crude membrane fractions (Sier et al. 1993; Okusa et al. 1999). A previous paper on the PA activity in the developing nervous tissue demonstrated that the estimation of the total amount of PA activity and also of the specific activity is more reliably assayed in soluble fractions derived by ultracentrifugation from a membrane fraction submitted to a previous Triton X-100 treatment (Pereyra-Alfonso et al. 1995). So, we corroborated this result in the gastrointestinal tumors and the adjacent "morphologically normal tissues".

The present study was designed to analyze the possible existence of significant correlations between the activity of the PA system and the stages of tumor progression. Analyses were performed in both the tumor tissues and the "normal" digestive tract segment adjacent to the tumor mass. Global PA activity, the activity of each PA isoform, and PAI-1 expression were analyzed.

\section{Materials and methods}

\section{Patients' characteristics and tissue samples}

Forty-four patients enrolled in this work were diagnosed with primary gastrointestinal carcinomas and underwent surgical resection at "Diego Thompson" Hospital (Buenos Aires State, Argentina) between February 2002 and February 2004. The surgical resection involved the tumor mass plus a segment of the "normal" digestive tube adjacent to the tumor.

Steroidal anti-inflammatory drugs (Viaje et al. 1977), non-steroidal anti-inflammatory drugs (Pelletier et al. 1997; Li et al. 2002; Sadowski and Steinmeyer 2002; Iwamoto et al. 2003), and selective COX-2 inhibitors ( $\mathrm{Li}$ et al. 2002; Berger et al. 2003; Khan et al. 2004; Nishikawa et al. 2004) reduce the expression of the components of the PA system. For this reason, five patients medicated with non-steroidal anti-inflammatory drugs or aspirin at any moment of the 14-day period previous to the surgery were excluded from this analysis. None of the patients received selective COX-2 inhibitors or steroidal anti-inflammatory drugs.

Fragments of gastrointestinal carcinomas and of the corresponding "morphologically normal" digestive tract segment adjacent to the tumor mass (taken at approximately 10-20 cm from the tumor border) were obtained. Samples taken from the "normal" digestive tract segment adjacent to the tumor are named as "morphologically normal tissue" or "normal tissue" in this article. Detailed histological examination of these "normal tissue" fragments demonstrated that they were not contaminated with tumor cells. As it is known that inflammatory processes increase PA activity (Pelletier et al. 1997; Herszényi et al. 2000; Sadowski and Steinmeyer 2002; Iwamoto et al. 2003; Khan et al. 2004), four samples were eliminated because histological studies detected inflammatory features in the "normal" tissue samples. So, 35 paired "normal" and tumor samples were finally included in this work.

Fragments of tumor and "normal tissues" were frozen quickly and stored at $-20^{\circ} \mathrm{C}$. The patients' clinical and histopathological data were evaluated and recorded (Table 1).

Patients were classified according to the criteria given by the TNM Classification and Stage grouping of the American Joint Committee on Cancer Staging (AJCC) (Greene et al. 2002).

The study was approved by the Ethics Committee of the "Diego Thompson" Hospital (Argentina).

\section{PA extraction procedure}

Total homogenates (THs) from the fragments of tumor and "normal tissues" obtained from three patients were prepared in nine volumes of $0.1 \mathrm{M}$ Tris- $\mathrm{HCl}$ buffer, $\mathrm{pH}$ 8.1 and ultracentrifuged at $100,000 \mathrm{~g}$ for $1 \mathrm{~h}$ to separate a 
Table 1 Patients' clinical and histopathological characteristics $(n=35)$

\begin{tabular}{|c|c|c|c|}
\hline \multicolumn{2}{|l|}{ Age (Years) } & \multirow{2}{*}{\multicolumn{2}{|c|}{$\begin{array}{l}\text { Lymph node } \\
\text { status }\end{array}$}} \\
\hline Median (range) & $64(33-89)$ & & \\
\hline Male : female & $1.18: 1$ & $\begin{array}{l}\text { N0 } \\
\text { N1 } \\
\text { N2 }\end{array}$ & $\begin{array}{l}15 \\
12 \\
8\end{array}$ \\
\hline
\end{tabular}

\begin{tabular}{llll}
\hline Location & \multicolumn{3}{c}{ Metastasis } \\
\hline Stomach & 7 & M0 & 28 \\
Colon & 22 & M1 & 7 \\
Rectum & 6 & & \\
\hline Tumor classification & Stage & \\
\hline T1 & 1 & I & 3 \\
T2 & 6 & II & 11 \\
T3 & 25 & IIIA & 3 \\
T4 & 3 & IIIB & 8 \\
& & IIIC & 3 \\
& & IV & 7 \\
\hline
\end{tabular}

soluble fraction (SF) and a crude membrane fraction (CMF). Triton X-100 was added to aliquots of THs and SFs up to a final concentration of $0.5 \%$, incubated for $1 \mathrm{~h}$ at $0-4^{\circ} \mathrm{C}$, and stored at $-20^{\circ} \mathrm{C}$. CMF was resuspended in the same buffer containing $0.5 \%$ Tritón X-100 and ultracentrifuged at $100,000 \mathrm{~g}$ for $1 \mathrm{~h}$ to obtain a supernatant (E1) and a second pellet 2 (P2). P2 was subjected to five additional cycles of resuspension, Triton X-100 treatment, and ultracentrifugation at $100,000 \mathrm{~g}$ for $1 \mathrm{~h}$ to obtain supernatants $2-6$ (second to sixth extractions, E2 to E6) (Fig. 1a). All these extracts were stored at $-20^{\circ} \mathrm{C}$. After thawing, samples of these extracts were used to determine: (a) protein concentration by Lowry method (Lowry et al. 1951) and (b) PA activity by caseinolytic assay. As it can be seen in Fig. 1b, the E1 fraction displays the highest value of PA activity. Therefore, the E1 fraction was used to assay PA activity.

\section{Caseinolytic assay}

PA activity was measured by a radial caseinolytic assay in casein-agar plates containing $5.6 \mathrm{mg} / \mathrm{ml}$ dry skim milk dissolved in Tris- $\mathrm{HCl} 0.2 \mathrm{M} \mathrm{pH} 8$ buffer, $2.5 \%$ agar, and $2 \mu \mathrm{g} / \mathrm{ml}$ of plasminogen. The samples were incubated at $37^{\circ} \mathrm{C}$ in a humidified chamber for $24 \mathrm{~h}$ for the assessment of: (a) total PA activity and (b) t-PA activity. The t-PA activity was assayed in casein-agar plates containing $1 \mathrm{mM}$ amiloride (an $\mathrm{u}-$ PA selective inhibitor) (Vassalli and Belin 1987). The difference in activity between (a) and (b) was considered as the u-PA activity. Control assays demonstrate that $1 \mathrm{mM}$ amiloride completely inhibits the u-PA standard activity (purchased from Serono, Buenos Aires, Argentina) and that it does not affect a t-PA standard activity (t-PA from Bowes melanoma, a gift from Dr D. Collen, University of Leuven, Belgium). PA activity was expressed in terms of $\mathrm{mIU} / \mathrm{mg}$ protein of tissue extracts. Plasminogen-free casein-agar plates were used to detect non-specific protease activity in (E1) samples obtained from the tumor and "normal" tissue samples.

\section{Quantification of PAI-1 antigen in tissue extracts}

Content of PAI-1 in E1 fraction was assayed by commercially available ELISA kit according to the method provided by the manufacturer (Imubind ${ }^{\circledR}$ PAI-1 ELISA Kit from American Diagnostica, Greenwich). Values of PAI-1 content were expressed in $\mathrm{ng} / \mathrm{mg}$ protein of tissue extracts.

\section{Statistical analysis}

Results were expressed as mean \pm SE. Comparisons of PA activity or PAI-1 content between "normal" and tumor tissues were assessed using Student $t$-test for paired data. Correlations between PA activity, u-PA activity, t-PA activity, or PAI-1 content in tumor and "normal tissues" were determined using the Pearson correlation coefficient. Linear and polynomial correlations were assessed between PA activity and the degree of tumor progression. Comparisons of PA activity or PAI-1 content among patients with different degree of tumor progression were assessed by using one way analysis of variance (ANOVA), followed by Tukey's multiple comparison post ANOVA test and two ways ANOVA. Differences and correlations were considered statistically significant at $P<0.05$.

\section{Results}

PA activity throughout the extraction procedure

The protocol of repetitive extraction procedure shows that at least six successive cycles of resuspension, Triton treatment, and ultracentrifugation are necessary to completely solubilize the PA activity of the CMFs obtained from the tumor and "normal tissues" (Fig. 1b). The highest PA activity corresponds to the E1 fraction. These results show that the determination of PA activity in THs or CMFs underestimates the total activity of tissues and that the E1 fraction offers the best estimation of PA activity. Thus, all the values of PA activity described in this work correspond to those measured in the E1 fraction.

The protease activity found in all the above-mentioned fractions completely disappears when the samples are seeded on plasminogen-free casein-agar plates, indicating that the enzymatic activity is plasminogendependent. 


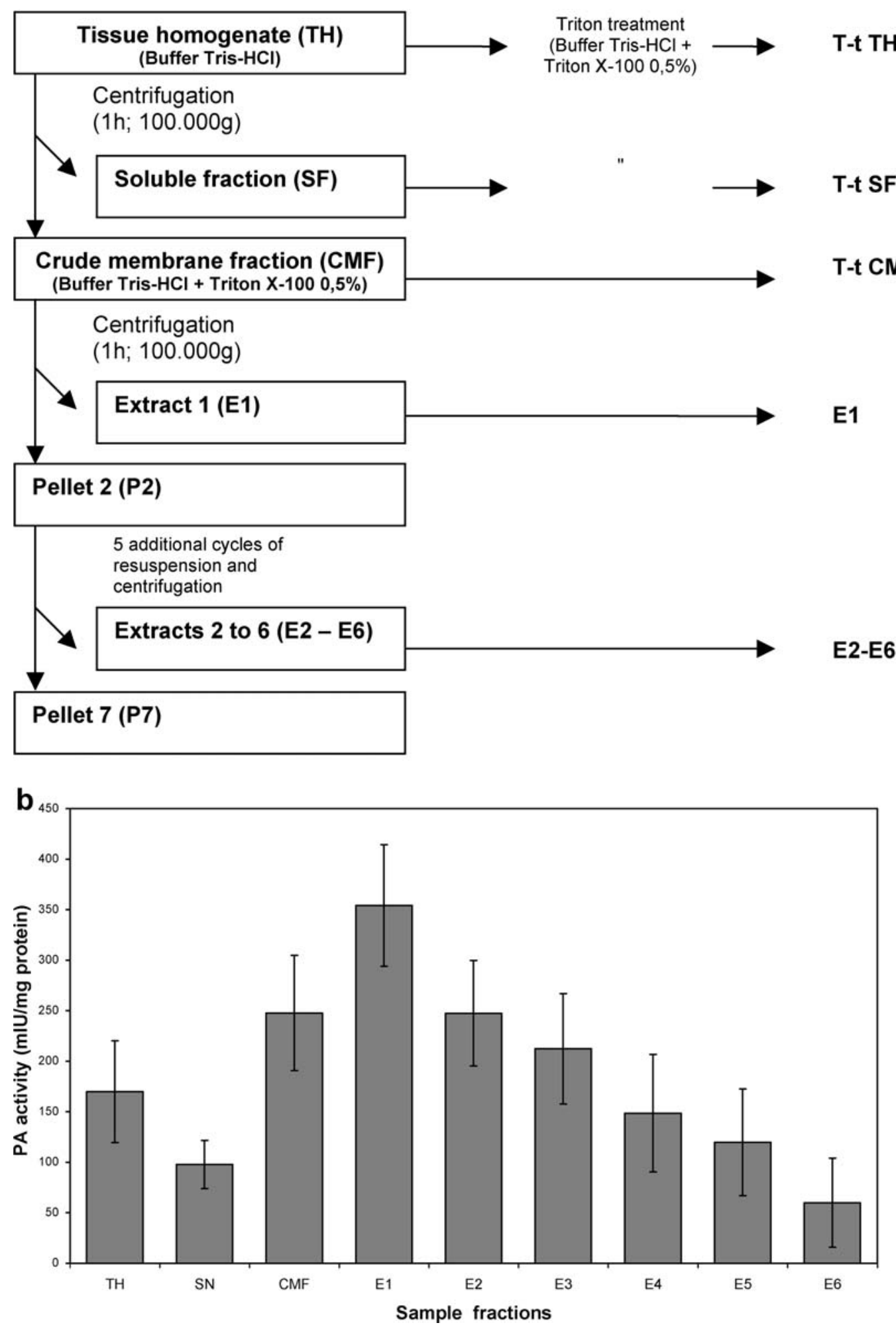

Fig. 1 a Diagrammatic representation of the protocol used for PA extraction. For a detailed description see Materials and methods. b Amounts of PA activity measured in samples from "normal" and tumor gastrointestinal tissues obtained by a repetitive extraction procedure of Triton X-100 treatment and ultracentrifugation. PA activity is significantly higher in E1 than in any other fractions
(TH, SF, CMF, E2 to E6) $P<0.05$ (Paired Student $t$-test). Each sample is expressed as $\mathrm{mIU} / \mathrm{mg}$ protein. Mean $\pm \mathrm{SE}$ of six independent samples (three tumors and three corresponding "normal" counterparts) measured by triplicate are represented. $T-t$ Triton X-100 treated 
Comparison of PA system between tumor and "normal tissues"

Table 2 shows the results of paired statistical analyses performed on the whole population of patients. It is shown that the total amount of PA activity, the u-PA activity, and the PAI-1 expression are significantly higher in tumor tissues than in the corresponding "normal tissues". The t-PA activity, however, does not significantly differ between tumor and "normal tissues".

Table 3 shows a statistically significant positive correlation between the total PA activities produced by the tumor and "normal tissues". The determination coefficient $\left(R^{2}=0.24\right)$ indicates that around $24 \%$ of the variability of one of them can be accounted for the variability of the other one. The u-PA activities produced by the

Table 2 Comparison of PA activities and PAI-1 expression between tumor and "normal tissues"

\begin{tabular}{lllll}
\hline & Tumor & Normal & $P$ value & $n$ \\
\hline $\begin{array}{l}\text { Total PA } \\
\text { (mIU/mg prot) }\end{array}$ & $190.3 \pm 17.54$ & $51.53 \pm 6.94$ & $P<0.0001$ & 35 \\
t-PA (mIU/mg prot) & $35.83 \pm 4.78$ & $31.10 \pm 5.26$ & $P=0.49$ & 33 \\
u-PA (mIU/mg prot) & $152.4 \pm 16.4$ & $22.63 \pm 4.87$ & $P<0.0001$ & 33 \\
PAI-1 (ng/mg prot) & $8.63 \pm 1.87$ & $1.15 \pm 0.36$ & $P=0.0008$ & 28 \\
\hline
\end{tabular}

Table 3 Correlations of PA, u-PA, and t-PA activities between the "normal" and tumor tissues

\begin{tabular}{llll}
\hline & PA activity & u-PA activity & t-PA activity \\
\hline$r$ & 0.4885 & 0.5663 & 0.1099 \\
$r^{2}$ & 0.2386 & 0.3207 & 0.0121 \\
$P$ & 0.0029 & 0.0006 & 0.5425 \\
$n$ & 35 & 33 & 33 \\
\hline
\end{tabular}

tumor and "normal tissues" are also positively correlated. In this case, the determination coefficient is higher $\left(R^{2}=0.32\right)$. The t-PA activities produced by the tumor and "normal tissues" are not correlated.

The levels of u-PA and t-PA activities are highly variable in both the tumor and the "normal tissues" in the entire sample of patients, but the correlation shown in Table 3 reveals synchronous fluctuations of u-PA activity in the tumor and "normal tissues" in each patient.

Table 4 shows that the level of total PA activity is differentially influenced by u-PA and t-PA production in the tumor and "normal tissues". The variability observed in the total PA activity in tumor tissues is largely determined by the level of u-PA production $\left(R^{2}=0.92\right)$. The influence of the t-PA produced by the tumor cells is less relevant $\left(R^{2}=0.30\right)$. The level of total PA activity in the "normal tissues" is almost equally determined by uPA $\left(R^{2}=0.45\right)$ and t-PA $\left(R^{2}=0.54\right)$ production.

We also analyzed the correlation between total PA, u-PA, or t-PA activities and PAI-1 expression in the tumor and "normal tissues". As can be seen in Table 5, there is a positive correlation between u-PA activity and PAI-1 expression in both the tumor $\left(R^{2}=0.33\right)$ and "normal tissues" $\left(R^{2}=0.29\right)$, but there is no statistically significant correlation between PA or t-PA activities and PAI-1 expression.

To elucidate the relationship between both types of PA activity present in the "normal" and tumor tissues, the u-PA activity/t-PA activity ratio was determined. We found a u-PA/t-PA ratio of 0.73 in the "normal tissues" and a $\mathrm{u}-\mathrm{PA} / \mathrm{t}-\mathrm{PA}$ ratio of 4.25 in the tumor tissues.

Correlations between levels of PA, u-PA, or t-PA activities and tumor stages

Figure 2 tries to find a statistical correlation between PAs activities and the degree of tumor progression

Table 4 Correlations between total PA activity and the activity of both isoforms of PA in "normal" and tumor tissues

\begin{tabular}{|c|c|c|c|c|}
\hline & $\begin{array}{l}\text { PA and u-PA activities } \\
\text { in tumor tissues }\end{array}$ & $\begin{array}{l}\text { PA and t-PA } \\
\text { activities in } \\
\text { tumor tissues }\end{array}$ & $\begin{array}{l}\text { PA and u-PA activities } \\
\text { in "normal tissues" }\end{array}$ & $\begin{array}{l}\text { PA and t-PA activities } \\
\text { in "normal tissues" }\end{array}$ \\
\hline$r$ & 0.9572 & 0.5503 & 0.6729 & 0.7318 \\
\hline$r^{2}$ & 0.9163 & 0.3029 & 0.4527 & 0.5355 \\
\hline$P$ & $<0.0001$ & 0.0009 & $<0.0001$ & $<0.0001$ \\
\hline$n$ & 33 & 33 & 33 & 33 \\
\hline
\end{tabular}

Table 5 Correlations between PAI-1 content and the PA, u-PA, or t-PA activities in "normal" and tumor tissues

\begin{tabular}{|c|c|c|c|c|c|c|}
\hline & $\begin{array}{l}\text { PAI-1 content and } \\
\text { u-PA activity in } \\
\text { tumor tissues }\end{array}$ & $\begin{array}{l}\text { PAI-1 content } \\
\text { and t-PA activity } \\
\text { in tumor tissues }\end{array}$ & $\begin{array}{l}\text { PAI-1 content } \\
\text { and PA activity } \\
\text { in tumor tissues }\end{array}$ & $\begin{array}{l}\text { PAI-1 content } \\
\text { and U-PA activity } \\
\text { in "normal tissues" }\end{array}$ & $\begin{array}{l}\text { PAI- } 1 \text { content and } \\
\text { t-PA activity in } \\
\text { "normal tissues" }\end{array}$ & $\begin{array}{l}\text { PAI-1 content } \\
\text { and PA activity } \\
\text { in "normal tissues" }\end{array}$ \\
\hline$r$ & 0.5703 & -0.1442 & -0.0536 & 0.5415 & -0.0202 & -0.3038 \\
\hline$r^{2}$ & 0.3252 & 0.0208 & 0.0029 & 0.2932 & 0.0004 & 0.0923 \\
\hline$P$ & 0.0024 & 0.4821 & 0.7949 & 0.0029 & 0.9188 & 0.1161 \\
\hline$n$ & 26 & 26 & 26 & 28 & 28 & 28 \\
\hline
\end{tabular}


a

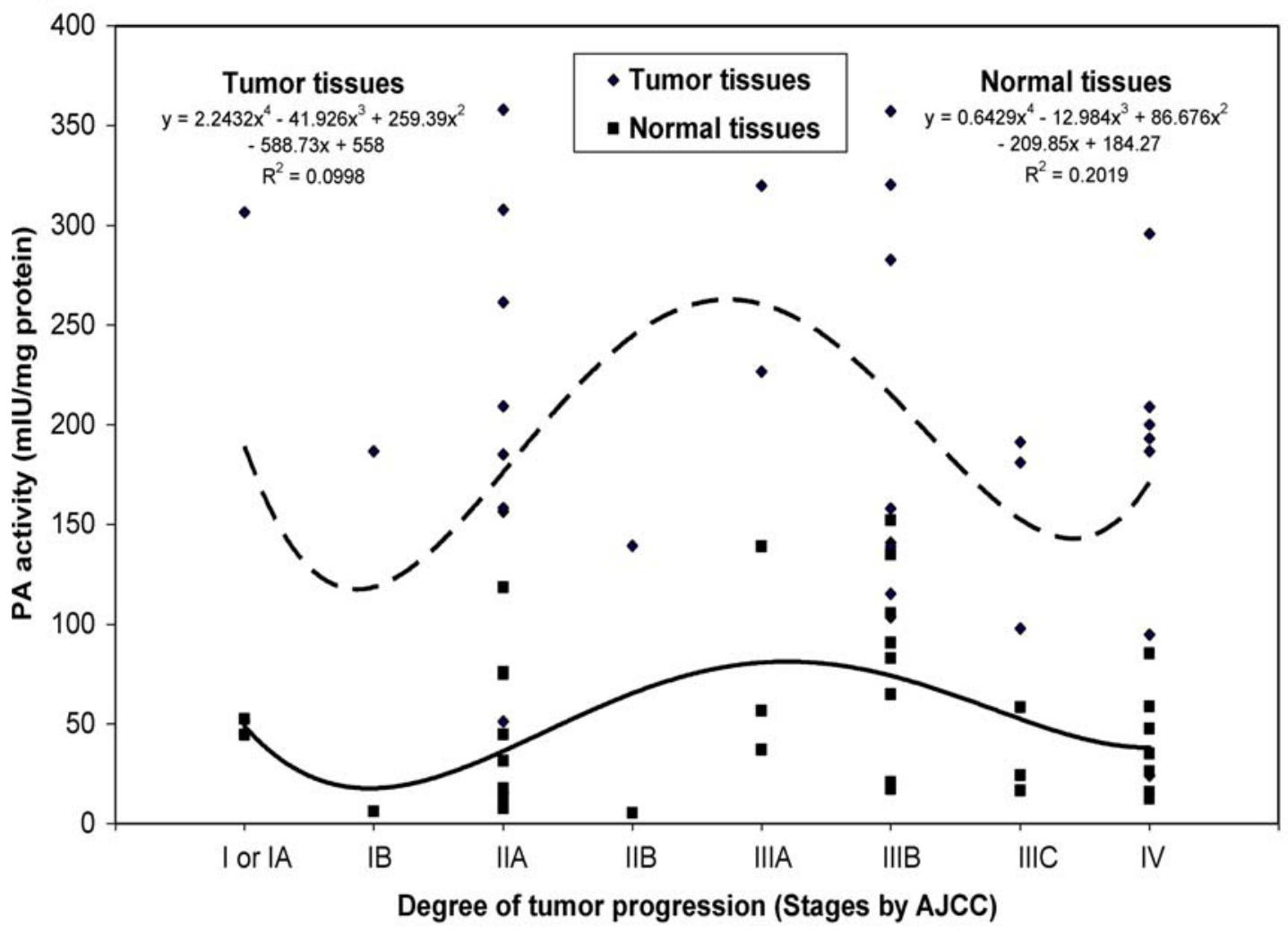

b

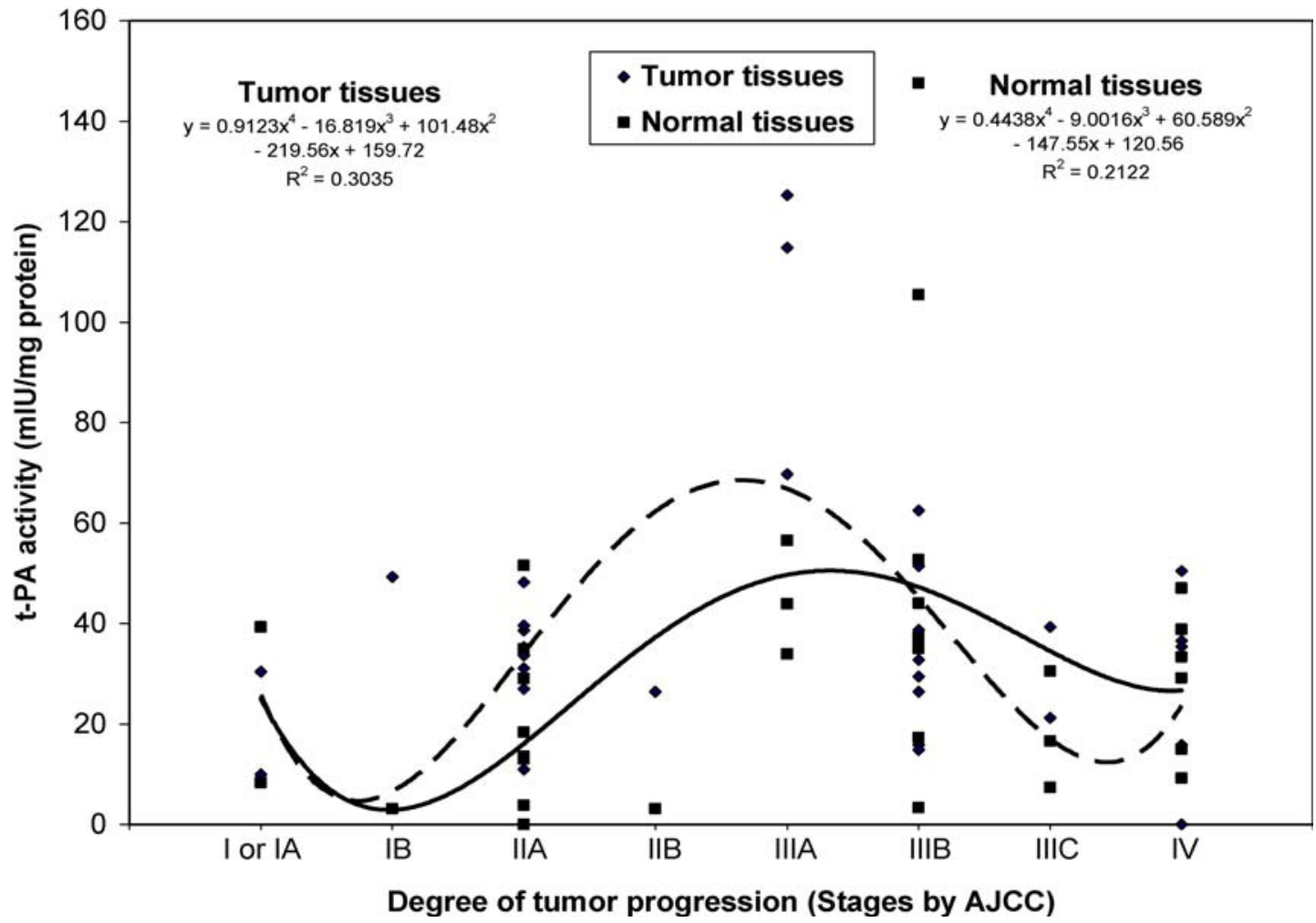

Fig. 2 Polynomial correlations between total PA activity (a), t-PA activity (b), and u-PA activity (c) - assayed in both the tumor and "normal tissues" - and the degree of tumor progression according to the stages of AJCC (Greene et al. 2002) (I or IA, IB, IIA, IIB, IIIA, IIIB, IIIC, and IV). This figure shows that a good fitting can be obtained by a fourth order polynomial correlation. Curve lines obtained by the polynomial fit consistently show a tendency to a higher total PA (a) and t-PA activity (b), in both the tumor and "normal tissues", at stages IIIA and IIIB. (- - -): Tumor tissues, ( ) : "Normal tissues" 


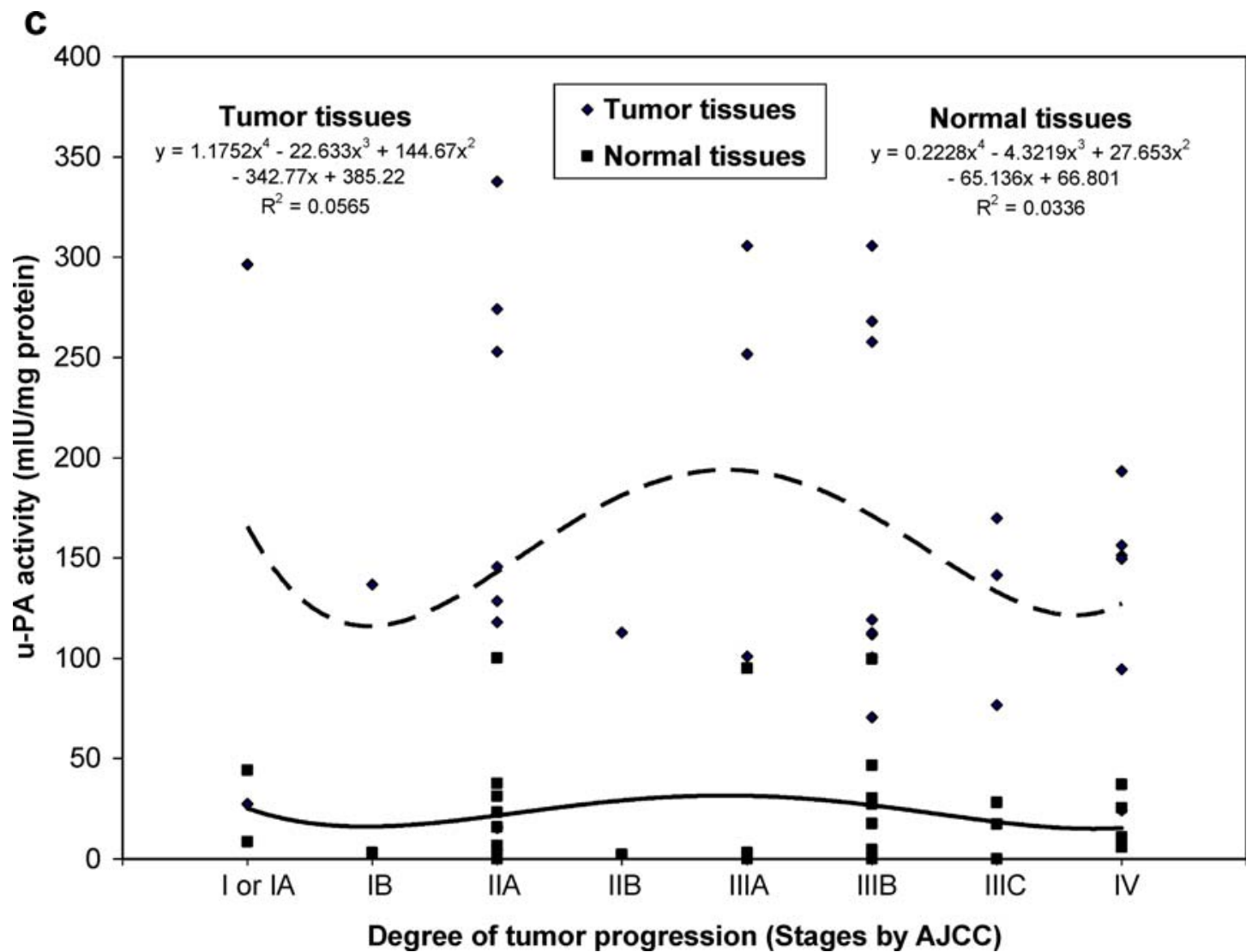

Fig. 2 (Contd.)

according to the stages of AJCC (Greene et al. 2002). The absence of a linear correlation between PA, u-PA, or t-PA activity and the stage of tumor progression, either in the tumor or "normal tissues", can be appreciated. A better fitting can be obtained by a fourth order polynomial correlation. Curve lines obtained by the polynomial fit consistently show a tendency to a higher total PA and t-PA activity, in both the tumor and "normal tissues", at stages IIIA (colorectal cancer: T1 or T2 N1 M0, gastric cancer: T2 N2 M0 or T3 N1 M0 or T4 N0 M0) and IIIB (colorectal cancer: T3 or T4 N1 M0, gastric cancer: T3 N2 M0), and then the activity tends to decrease.

In order to test whether the patients of stages IIIA and IIIB in fact display significantly higher levels of these PAs activities than the others, patients were reclassified into three groups:

(1) Group 1 includes stages I (colorectal cancer: T1or T2 N0 M0, gastric cancer: T1 N0 or N1 M0 or T2 N0 M0) and II (colorectal cancer: T3 or T4 N0 M0, gastric cancer: T1, N2 M0 or T2 N1 M0 or T3 N0 M0). As patients with gastric carcinomas had no lymphatic node invasion, all patients presented local tumor without lymphatic node invasion.

(2) Group 2 includes stages IIIA and IIIB. These patients have local tumor and lymphatic node invasion (not more than three nodes for colorectal carcinomas and not more than 15 nodes for gastric carcinomas).

Table 6 Comparison of PA system among groups of patients with different degree of tumor progression

\begin{tabular}{|c|c|c|c|c|c|c|c|c|c|}
\hline \multirow[t]{2}{*}{ Group } & \multirow[t]{2}{*}{ Stage } & \multicolumn{2}{|c|}{$\begin{array}{l}\text { Total PA activity } \\
\text { (mIU/mg protein) }\end{array}$} & \multicolumn{2}{|c|}{$\begin{array}{l}\text { t-PA activity } \\
\text { (mIU/mg protein) }\end{array}$} & \multicolumn{2}{|c|}{$\begin{array}{l}\text { u-PA activity } \\
\text { (mIU/mg protein) }\end{array}$} & \multicolumn{2}{|c|}{ PAI-1 (ng/mg protein) } \\
\hline & & Tumor & Normal & Tumor & Normal & Tumor & Normal & Tumor & Normal \\
\hline 1 & I II & $171.6 \pm 29.70$ & $37.24 \pm 9.03$ & $29.26 \pm 4.07$ & $17.09 \pm 4.59$ & $143.5 \pm 31.78$ & $21.63 \pm 7.70$ & $7.39 \pm 3.35$ & $1.56 \pm 0.95$ \\
\hline 2 & IIIA IIIB & $234.9 \pm 33.28$ & $81.94 \pm 14.30$ & $52.90 \pm 11.33$ & $52.46 \pm 12.26$ & $182.2 \pm 28.27$ & $29.58 \pm 11.1$ & $7.52 \pm 1.74$ & $0.95 \pm 0.18$ \\
\hline 3 & IIIC IV & $167.3 \pm 23.96$ & $38.07 \pm 7.54$ & $24.46 \pm 5.84$ & $25.23 \pm 4.60$ & $128.6 \pm 17.68$ & $15.6 \pm 4.08$ & $10.65 \pm 3.88$ & $0.86 \pm 0.39$ \\
\hline$P$ & & 0.23 & 0.008 & 0.032 & 0.009 & 0.42 & 0.545 & 0.72 & 0.69 \\
\hline$n$ & & 35 & 35 & 33 & 33 & 33 & 33 & 29 & 29 \\
\hline
\end{tabular}


(3) Group 3 includes stages IIIC (colorectal cancer: any T N2 M0) and IV (colorectal cancer: any T any N $\mathrm{M} 1$, gastric cancer: $\mathrm{T} 4 \mathrm{~N} 1$ or $\mathrm{N} 2$ or $\mathrm{N} 3 \mathrm{M} 0$ or $\mathrm{T} 1$ or $\mathrm{T} 2$ or T3 N3 M0 or any T any N M1) (Greene et al. 2002). These patients have massive local involvement and/or invasion of four or more regional lymphatic nodes in colorectal carcinomas or more than 15 regional nodes in gastric carcinomas, and/or distant metastasis.

One way ANOVA and Tukey's post test were applied to find stage-dependent differences among the three groups (Table 6). The ANOVA indicates the absence of significant differences in the total PA activity among the tumor tissues of the three groups. In contrast, the global PA activity in the "normal tissues" is significantly higher in Group 2. With regard to the t-PA activity, Group 2 also exhibits significant higher activity than the other groups in both the tumor and "normal tissues". On the other hand, the u-PA activity and the PAI-1 content do not present any significant difference among the three groups in the tumor or "normal" tissues.

Two ways ANOVA shows that the variability of total PA activity is due to both the tissue type - tumor versus "normal tissues"- $(P<0.0001, n=35)$ and the degree of tumor progression $(P=0.025, n=35)$. For t-PA activity, the variability is due to the degree of tumor progression $(P=0.0005, n=33)$ but not to the tissue type $(P=0.54$, $n=33$ ). The opposite situation is true for u-PA activity and PAI-1 content, for which the variability is due to the tissue type (u-PA $P<0.0001, n=33$; PAI-1 $P=0.0003$, $n=29$ ) but not to the degree of tumor progression (u-PA $P=0.27, n=33$; PAI-1 $P=0.78, n=29$ ). These results imply that the difference in the total PA activity between the tumor and "normal tissues" is entirely attributable to the difference in u-PA activity, whereas the difference in total PA activity assayed in the "normal tissues" among groups of different degree of tumor progression is entirely attributable to the difference in t-PA activity.

\section{Discussion}

Assays of PA activity in the tumor tissues are usually performed in Triton X-100-treated THs or CMFs (Sier et al. 1993; Okusa et al. 1999). These values of PA activities are considered as the characteristic enzyme activity of the tissue and they are used for comparative purposes. This work shows that the PA activity of a tissue can only be estimated by a repetitive extraction procedure. Six cycles of pellet resuspension, Triton X100 treatment, and ultracentrifugation are needed to completely extract the PA activity from the tumor and "normal tissues" and total activity is the sum of all the activity extracted. Besides, better estimation of PA activity is obtained by assaying it on E1 fraction (Fig. 1). This is consistent with the fact that a substantial amount of u-PA (Andreasen et al. 2000) and t-PA (Diaz et al. 2004) are normally bound to membranes by interactions with high affinity binding sites. Given that such interactions are essential for extracellular matrix degradation (Andreasen et al. 2000) and then for local tumor invasion and metastatic dissemination, we chose the E1 fraction as the sample for determining the PA activity.

It was already well established that u-PA activity and PAI-1 expression are higher in tumor tissues than in their counterpart "normal tissues" (Sier et al. 1993; Verspaget et al. 1995; Herszenyi et al. 2000; Berger 2002). Present results confirm this notion.

A remarkable rise in u-PA/t-PA ratio from "normal" to tumor tissues was reported (Verspaget et al. 1995; Ganesh et al. 1994, 1996, 1997). We found a u-PA/t-PA ratio of 0.73 in the "normal tissues" and a u-PA/t-PA ratio of 4.25 in the tumor tissues. According to our results, the difference between these ratios can be explained by an increase in the u-PA activity in the tumor tissues because t-PA activity does not differ significantly between tumor and "normal tissues" (Table 2). These results suggest an up-regulation of u-PA in the tumor tissues instead of a switch of molecular type of PA. Several works support this idea (Andreasen et al. 2000; Sanz et al. 2002; Baker and Leaper 2003; Diaz et al. 2004; Seiler et al. 2004).

Both u-PA activity and PAI-1 content display higher levels in tumor than in "normal tissues". This agrees with the positive correlation found between both of them in the tumor and "normal tissues". It is known that PAI-1 over-expression, apart from inhibiting PA activity, facilitates neoplastic invasion probably by inducing cell detachment (Noel et al. 2004) or regulating vascular remodeling (Fox et al. 2001). It is likely that u-PA and PAI-1 expression could be up-regulated by common upstream factors related to tumor invasion. This hypothesis is supported by the finding that MET oncogene produces up-regulation of PAI-1 and COX-2 genes (Boccaccio et al. 2005). Besides, COX-2 increases invasion and metastatic capability of tumors by up-regulating the u-PA expression ( $\mathrm{Li}$ et al. 2002; Singh et al. 2005). Consistently, COX inhibitors and selective COX-2 inhibitors decrease u-PA expression and reduce the rate of tumor invasion and metastatic spread (Li et al. 2002; Berger et al. 2003; Evans and Sloan Stakleff 2004; Nishikawa et al. 2004; Singh et al. 2005).

It is interesting to note that the amounts of u-PA and PAI-1 produced by the tumor tissues are significantly higher than that of their corresponding surrounding "normal tissues", but the amount of t-PA produced by tumor tissues does not differ from that of "normal tissues". Does this mean that "normal tissues" also display an abnormally high level of t-PA production? It is also interesting to note that the highest level of total PA activity in "normal tissues" in patients of stages IIIAIIIB coincides with an increase in t-PA activity during the same stages in both the tumor and "normal tissues". Does this mean that the high level of t-PA produced by the tumor tissues also results in a high level of production in the "normal tissues"? Does this mean that the mech- 
anism responsible for increasing the t-PA production operates on both the tumor and "normal tissues"? The answer seems to be negative because there is no positive correlation between those parameters (Table 3).

Total PA activity in "normal tissues" was significantly higher in patients of stages IIIA and IIIB. As it can be deduced from Table 6 , this increase in total PA is attributable to the increase in t-PA production. According to these results, it is the level of t-PA activity in "normal tissues" the parameter that best correlates with the degree of tumor progression.

The t-PA activity undergoes consistent changes in the tumor and "normal tissues" as a function of tumor progression, corresponding the highest level to patients of stages IIIA-IIIB. This pattern of changes strictly coincides with the pattern of total PA activity in "normal tissues". This situation can be explained by the different relevance that each isoform possesses in determining the total PA activity. The level of total PA activity in tumor tissues does not strongly depend on the t-PA activity (Table 4). Then, there is not any significant difference in the total PA activity in the tumor tissues among the three groups of tumor progression. In contrast, the total PA activity in "normal tissues" is equally determined by both the u-PA and the t-PA (Table 4) and the influence of the t-PA activity is large enough to introduce significant differences among the three groups of patients.

Several of our results indicate that "normal" segments adjacent to a tumor mass display an empathic behavior with tumor tissues in many senses: (a) The level of t-PA produced by the tumor and "normal tissues" does not differ (Table. 2). (b) Although the mean values of the total PA activity in the tumor and "normal tissues" significantly differ, there is a statistically significant correlation between PA production in the tumor and "normal tissues" (Table 3). (c) This correlation is mainly attributable to the pattern of u-PA produced by both the tumor and "normal tissues", since u-PA activity in both of them positively correlates (Table 3 ). This implies that tumor and "normal tissues" display similar variability, in other words, they fluctuate synchronously. (d) With regard to the t-PA production, there is no correlation between the tumor and "normal tissues" (Table 3). This implies that t-PA activity fluctuates independently in both of them. However, they are similar in another way: the mean value of t-PA activity does not differ in the tumor and "normal tissues" (Table. 2). (e) There is a statistically significant correlation between the level of t-PA activity in the tumor tissues and the stage of tumor progression (the level of t-PA production is significantly higher in patients of stages IIIA-IIIB). Similarly, the level of t-PA activity in "normal tissues" also positively correlates with the stage of tumor progression (the level of t-PA production is significantly higher in patients of stages IIIA-IIIB) (Fig. 2b and Table 6).

Two ways ANOVA shows that the variability of total PA activity is due to both: (1) the tissue type (PA shows higher activity in tumor than in "normal tissues") and (2) the degree of tumor progression (PA shows higher activity in "normal tissues" of patients of stages IIIA and IIIB). For t-PA, the variability of activity is due to the degree of tumor progression (t-PA activity is higher in stages IIIA and IIIB) but not to the tissue type (there is no difference in the levels of activity between the "normal" and tumor tissues). The opposite situation is true for u-PA activity and PAI-1 content. u-PA presents higher activity and PAI-1 shows higher content in tumor tissues than in "normal" ones, but they do not show any different levels associated with the degree of tumor progression. So, the variability of both of them is due to the tissue type but not to the tumor progression. These results suggest that the difference in total PA activity between the tumor and "normal tissues" is attributable to the up-regulation of u-PA activity in the tumor tissues, whereas the difference in the total PA activity assayed in the "normal tissues" among groups of different degree of tumor progression is attributable to the difference in t-PA activity.

Taken together, all these data indicate that the "morphologically normal tissues" adjacent to a carcinoma exhibit an abnormal biological behavior. This agrees with the fact that in a model of colon cancer induced by 1,2-dimethylhidrazine, the progenitor cells of the crypts localized in mucosa of normal appearance present a maturation arrest (Lipkin 1974). Besides, the low level of t-PA in normal mucosa from patients with gastrointestinal carcinomas is associated with a poor overall survival (Ganesh et al. 1994, 1996, 1997). These data apparently differ from our results, however, it is likely that the groups of patients with low t-PA in normal mucosa and poor survival could correspond to patients of stages IIIC-IV which display low t-PA activity in this work (Table 6) (Ganesh et al. 1994, 1996). The fact that "normal tissues" display an abnormal-like behavior and that the activity of PA system is associated with the degree of tumor progression supports the idea that the activity of PA system in "normal tissues" could influence the tumor progression. It was suggested that these changes in the PA system could represent an inflammatory response against the tumor (Verspaget et al. 1995). Another possibility is that these changes of PA could contribute to tumor progression. Studies on different human neoplasias show that the stromal cells located within the tumor interact with neoplastic cells and express components of the PA system, suggesting that stromal cells participate in cancer invasion and could have profound implications in tumor evolution (Grodahl-Hansen et al. 1991; Okusa et al. 1999; Kloblinski et al. 2000; Frandsen et al. 2001; Illemann et al. 2004). Our data suggest that anatomically and histologically "normal tissues" located as far as $20 \mathrm{~cm}$ from the tumor border present abnormal behavior of the PA system that could be related to the tumor progression.

These data support the hypothesis that gastrointestinal carcinoma could be considered as a disease of the entire mucosa (Zajicek 1993). This is a relevant notion in 
tumor biology because it could change the notion of a "normal tissue" surrounding a tumor and it could introduce drastic consequences in therapeutic strategy. This also suggests that studying the PA system in "morphologically normal tissues" adjacent to gastrointestinal carcinomas could be useful for evaluating patients with this pathology.

Acknowledgements We thank the Surgical Department of the "Diego Thompson" Hospital of San Martin for providing samples and Ms. Patricia López for the constructive critical review of the English language of the manuscript. This work was supported by grants from UBACYT and CONICET, Argentina.

\section{References}

Abe J, Urano T, Konno H, Erhan Y, Tanaka T, Nishino N, Takada A, Nakamura S (1999) Larger and more invasive colorectal carcinoma contains larger amounts of plasminogen activator inhibitor type1 and its relative ratio over urokinase receptor correlates well with tumor size. Cancer 86:2602-2611

Andreasen PA, Engelund R, Petersen HH (2000) The plasminogen activation system in tumor growth, invasion and metastasis. CMLS Cell Mol Life Sci 57:25-40

Baker EA, Leaper DJ (2003) The plasminogen activator and matrix metalloproteinase systems in colorectal cancer: relationship to tumour pathology. Eur J Cancer 39:981-988

Berger DH (2002) Plasmin/plasminogen system in colorectal cancer. World J Surg 26:767-771

Berger DH, O'Mahony CA, Sheng H, Shao J, Albo D, DuBois RN, Beauchamp RD (2003) Intestinal transformation results in transforming growth factor-beta-dependent alteration in tumor cell-cell matrix interactions. Surgery 133:568-579

Boccaccio C, Sabatino G, Medico E, Girolami F, Follenzi A, Reato G, Sottile A, Naldini L, Comoglio PM (2005) The MET oncogene drives a genetic programme linking cancer to haemostasis. Nature 434:396-400

Cho JY, Chung HC, Noh SH, Roh JK, Min JS, Kim BS (1997) High level of Urokinase-type plasminogen activator is a new prognostic marker in patients with gastric carcinoma. Cancer 79:878-883

Diaz VM, Hurtado M, Thomson TM, Reventos J, Paciucci R (2004) Specific interaction of tissue-type plasminogen activator (t-PA) with annexin II on the membrane of pancreatic cancer cells activates plasminogen and promotes invasion in vitro. Gut 53:993-1000

Duffy MJ, Duggan C (2004) The urokinase plasminogen activator system: a rich source of tumour markers for the individualised management of patients with cancer. Clin Biochem 37:541-548

Evans DM, Sloan Stakleff KD (2004) Control of pulmonary metastases of rat mammary cancer by inhibition of uPA and COX-2, singly and in combination. Clin Exp Metastasis 21:339-346

Frandsen TL, Holst-Hansen C, Nielsen BS, Christensen IJ Nyengaard JR, Carmeliet P, Brunner N (2001) Direct evidence of the importance of stromal urokinase plasminogen activator (uPA) in the growth of an experimental human breast cancer using a combined uPA gene-disrupted and immunodeficient xenograft model. Cancer Res 61:532-537

Fox SB, Taylor M, Grondahl-Hansen J, Kakolyris S, Gatter KC, Harris AL (2001) Plasminogen activator inhibitor-1 as a measure of vascular remodelling in breast cancer. J Pathol 195:236243

Fujii T, Obara T, Tanno S, Ura H, Kohgo Y (1999) Urokinasetype plasminogen activator and plasminogen activator inhibitor-1 as a prognostic factor in human colorectal carcinomas. Hepatogastroenterology 46:2299-2308
Ganesh S, Sier CFM, Griffioen G, Vloedgraven HJM, de Boer A, Welvaart K, van de Velde CJH, van Krieken JHJM, Verheijen JH, Lamers CBHW, Verspaget HW (1994) Prognostic relevance of plasminogen activators and their inhibitors in colorectal cancer. Cancer Res 54:4065-4071

Ganesh S, Sier CFM, Heerding MM, van Krieken JH, Griffioen G, Weelvaart K, van de Velde CJ, Verheijen JH, Lamers CB, Verspaget HW (1996) Prognostic value of the plasminogen activation system in patients with gastric carcinoma. Cancer 77:1035-1043

Ganesh S, Sier CFM, Heerding MM, van Krieken JH, Griffioen G, Welvaart K, van de Valde CJ, Verheijen JH, Lamers CB, Verspaget HW (1997) Contribution of plasminogen activators and their inhibitors to the survival prognosis of patients with Dukes' stage B and C colorectal cancer. Br J Cancer 75:1793-1801

Greene FL, Page DL, Fleming ID, Fritz A, Balch CM, Haller DG (eds) (2002) American Joint Committee on Cancer Staging Manual, 6th edn. Berlin, Springer-Verlag

Grondahl-Hansen J, Ralfkiaer E, Kirkeby LT, Kristensen P, Lund LR, Dano K (1991) Localisation of urokinase-type plasminogen activator in stromal cells in adenocarcinomas of the colon in humans. Am J Pathol 138:111-117

Heiss MM, Allgayer H, Gruetzner KU, Babic R, Jauch KW, Schildberg FW (1997) Clinical value of extended biologic staging by bone marrow micrometastases and tumor-associated proteases in gastric cancer. Ann Surg 226:736-744

Herszenyi L, Plebani M, Carraro P, De Paoli M, Roveroni G, Cardin R, Foschia F, Tulassay Z, Naccarato R, Farinati F (2000) Proteases in gastrointestinal neoplastic diseases. Clin Chim Acta 291:171-187

Illemann M, Hansen U, Nielsen HJ, Andreasen PA, Hoyer-Hansen G, Dano K, Nielsen BS (2004) Leading-edge myofibroblasts in human colon cancer express plasminogen activator inhibitor-1. Am J Clin Pathol 122:256-265

Iwamoto J, Takahashi K, Mizokami Y, Otsubo T, Miura S, Narasaka T, Takeyama H, Omata T, Shimokoube K, Matsuoka T (2003) Expression of urokinase-type plasminogen activator and its receptor in gastric fibroblasts and effects of nonsteroidal antiinflammatory drugs and prostaglandin. Dig Dis Sci 48:2247-2256

Kaneko T, Konno H, Baba M, Tanaka T, Nakamura S (2003) Urokinase-type plasminogen activator expression correlates with tumor angiogenesis and poor outcome in gastric cancer. Cancer Sci 94:43-49

Khan KMF, Howe LR, Falcone DJ (2004) Extracellular matrixinduced cyclooxygenase- 2 regulates macrophage proteinase expression. J Biol Chem 279:22039-22046

Kloblinski JE, Ahram M, Sloane BF (2000) Unraveling the role of proteases in cancer. Clin Chim Acta 291:113-135

Konno H, Baba M, Shoji T, Ohta M, Suzuki S, Nakamura S (2002) Cyclooxygenase-2 expression correlates with uPAR levels and is responsible for poor prognosis of colorectal cancer. Clin Exp Metastasis 19:527-534

Li G, Yang T, Yan J (2002) Cyclooxygenase-2 increased the angiogenic and metastatic potential of tumor cells. Biochem Biophys Res Commun 299:886-890

Lipkin M (1974) Phase 1 and phase 2 proliferative lesions of colonic epithelial cells in diseases leading to colonic cancer. Cancer 34:878-888

Lowry OH, Rosebrough NJ, Farr AL, Randall PJ (1951) Protein measurement with Folin phenol reagent. J Biol Chem 193:265275

Murata S, Eguchi Y, Terata N, Tani T, Kodama M (1998) Expression of HLA-DR and urokinase- type plasminogen activator in stage IV gastric cancer. Gastric Cancer 1:71-77

Nekarda H, Schmitt M, Ulm K, Wenninger A, Vogesang H, Becker K, Roder JD, Fink U, Siewert JR (1994) Prognostic impact of urokinase plasminogen activator and its inhibitor PAI-1 in completed resected gastric cancer. Cancer Res 54:2900-2907

Nishikawa M, Stapleton PP, Freeman TA, Gaughan JP, Matsuda T, Daly JM (2004) NS-398 inhibits tumor growth and liver metastasis of colon cancer through induction of apoptosis and 
suppression of the plasminogen activation system in a mouse model. J Am Coll Surg 199:428-435

Noel A, Maillard C, Rocks N, Jost M, Chabottaux V, Sounni NE, Maquoi E, Cataldo D, Foidart JM (2004) Membrane associated proteases and their inhibitors in tumour angiogenesis. J Clin Pathol 57:577-584

Okusa Y, Ichikura T, Mochizuki H (1999) Prognostic impact of stromal cell-derived urokinase-type plasminogen activator in gastric carcinoma. Cancer 85:1033-1037

Papadopoulou S, Scorilas A, Yotis J, Arnogianaki N, Plataniotis G, Agnanti N, Talieri M (2002) Significance of urokinase-type plasminogen activator and plasminogen activator inhibitor-1 (PAI-1) expression in human colorectal carcinomas. Tumour Biol 23:170-178

Pelletier JP, Mineau F, Fernandes J, Kiansa K, Ranger P, MartelPelletier J (1997) Two NSAIDs, nimesulide and naproxen, can reduce the synthesis of urokinase and IL-6 while increasing PAI-1, in human OA synovial fibroblasts. Clin Exp Rheumatol 15:393-398

Pereyra-Alfonso S, Scicolone G, Fiszer de Plazas S, Pecci Saavedra J, Flores V (1995) Current Triton X-100 treatments do not allow a complete plasminogen activator extraction from developing nervous tissue. Neurochem Res 2:137-142

Raigoso P, Junco A, Andicoechea A, Gonzalez A, Garcia-Muniz JL, Allende MT, Garcia-Moran M, Vizoso F (2000) Tissue-type plaminogen activator (tPA) content in colorectal cancer and in surrounding mucosa: relationship with clinicopathologic parameters and prognostic significance. Int $\mathbf{J}$ Biol Markers $15: 44-50$

Sadowski T, Steinmeyer J (2002) Differential effects of nonsteroidal antiinflammatory drugs on the IL-1 altered expression of plasminogen activators and plasminogen activator inhibitor-1 by articular chondrocytes. Inflamm Res 51:427-433

Sanz L, Vizoso F, Verez P, Allende MT, Corte MG, Abdel-Lah O, Martin A, Garcia-Muniz JL (2002) Prognostic significance of tissue-type plasminogen activator (tPA) content in gastric cancer and surrounding mucosa. Int J Biol Markers 17:169-176
Seiler N, Schneider Y, Gosse F, Schleiffer R, Raul F (2004) Polyploidisation of metastatic colon carcinoma cells by microtubule and tubuline interacting drugs: effects on proteolytic activity and invasiveness. Int J Oncol 25:1039-1048

Sier CFM, Verspaget HW, Griffioen G, Ganesh S, Vloedgraven HJM, Lamers CBHW (1993) Plasminogen activators in normal tissue and carcinomas of the human oesophagus and stomach. Gut 34:80-85

Singh B, Berry JA, Shoher A, Ramakrishnan V, Lucci A (2005) COX-2 overexpression increases motility and invasion of breast cancer cells. Int J Oncol 26:1393-1399

Skelly MM, Troy A, Duffy MJ, Mulcahy HE, Duggan C, Connell TG, O'Donoghue DP, Sheahan K (1997) Urokinase-type plasminogen activator in colorectal cancer: relationship with clinicopathological features and patient outcome. Clin Cancer Res 3:1837-1840

Stephens RW, Nielsen HJ, Christensen IJ, Thorlacius-Ussing O, Sorensen S, Dano K, Brünner N (1999) Plasma urokinase receptor levels in patients with colorectal cancer: relationship to prognosis. J Natl Cancer Inst 91:869-874

Vassalli JD, Belin D (1987) Amiloride selectively inhibits the urokinase-type plasminogen activator. FEBS Lett 214:187-191

Verspaget HW, Sier CFM, Ganesh S, Griffioen G, Lamers CBHW (1995) Prognostic value of plasminogen activators and their inhibitors in colorectal cancer. Eur J Cancer 31A:1105-1109

Viaje A, Slaga TJ, Wigler M, Weinstein IB (1977) Effects of antiinflammatory agents on mouse skin tumor promotion, epidermal DNA synthesis, phorbol ester-induced cellular proliferation and production of plasminogen activator. Cancer Res 37:15301536

Yang JL, Seetoo D, Wang Y, Ranson M, Berney CR, Ham JM, Russell PJ, Crowe PJ (2000) Urokinase type-plasminogen activator and its receptor in colorectal cancer: independent prognostic factors of metastasis and cancer-specific survival and potential therapeutic targets. Int J Cancer 89:431-439

Zajicek G (1993) Cancer colon is a disease of the entire colonic mucosa. Cancer J 6:309 